\title{
Research On Construction Traffic Safety Measures Based On FAHP Model In Hydropower Project
}

\author{
YANG Xiao-yan $^{1}$,XIE Xin-sheng ${ }^{2 *}$, NIU Ya-ping ${ }^{3}$, ZHU Xiao-long ${ }^{4}$,DENG Chang-qi ${ }^{5}$ \\ ${ }^{1}$ Master of Hydraulic engineering management, SiChuan University, China \\ ${ }^{2}$ Vice Professor of Hydraulic structure and Hydraulic engineering management, SiChuan University, China \\ ${ }^{3}$ Staff of WanHua Real Estate Agency, SiChuan,China. \\ ${ }^{4,5}$ Master of Hydraulic structure, SiChuan university, Chengdu, SiChuan, China \\ Emails: ${ }^{1}$ xiaoyan0616@126.com ; ${ }^{2} x x$ 66666@163.com
}

\begin{abstract}
With the rapid expansion of hydropower projects, Construction safety problem has become one of the bottlenecks for the development of hydropower industry. Combined with the construction of the diversion channel project of Guan Yinyan hydropower station, from the point of view of construction traffic safety, based on the result of the FAHP model, factors which influence the construction safety of the diversion channel project of Guan Yinyan hydropower station have been found, relative measures focuses on the approach to eliminate hazards and guarantee construction safety have been elaborated.
\end{abstract}

Keywords - construction safety measures ;FAHP model; safety evaluation ; Guan Yinyan hydropower station; diversion channel project

\section{Engineering Situation}

GuanYinyan hydropower ${ }^{[1]}$ station (the project) is located at the middle reach of the Jin Shajiang river, the juncture of Sichuan and Yun'nan province. It is one of the 8 cascade hydropower stations under national planning at the middle reach of Jin Shajiang river. The diversion channel project of GuanYinyan hydropower station is the prophase works, the planed excavated volume or freight volume is about 7.8 million $\mathrm{m}^{3}$, the highest daily traffic volume reaches 4558 . The project is with the characteristics of complicated construction procedures, tight construction period, high construction intensity, large scale, unfavorable construction conditions and geological conditions, meanwhile, the construction road condition is complicated and many large mechanical are involved in the project. Therefor, evaluating the safety of the project, based on which, taking corresponding measures to solve problems on construction traffic safety, is of vital importance.

\section{Construction Traffic Safety Evaluation Mo del based on The Fuzzy Analytic Hierarchy Process (FAHP)}

According to the engineering condition, factors that influence construction safety have been analysed. An construction traffic safety evaluation model possessing 5 first grade indexes (management factors, site technician factors, mechanical factors, material factors, construction road factors and natural environment factors, put these factors as $\left\{A_{1} 、 A_{2} 、 A_{3} 、 A_{4}\right.$ 、 $\left.A_{5} 、 A_{6}\right\}$ and 24 second grade indexes are established. Adopting expert evaluation method to build judgments matrix, calculating the maximized eigenvalue and eigenvector of each matrix, after normalization processing, we put the eigenvectors which meet the demand of consistence as the weight value of each influencing factor. Using the methods of fuzzy mathematics, comprehensive evaluation on construction traffic safety of the project has been obtained. Based on the established evaluation criterion, the influence degree of each factor can be got, according to references ${ }^{[2]}$, here are the results: By adopting formula:

$$
W_{i}=\sum_{j=1}^{4} f_{i j} p_{i j} \quad(i=1,2,3,4,5,6), \text { we get: } \mathrm{W}_{1}=3.627 ;
$$

$\mathrm{W}_{2}=3.335 ; \mathrm{W}_{3}=3.854 ; \mathrm{W}_{4}=3.792 ; \mathrm{W}_{5}=3.547 ; \mathrm{W}_{6}=3.236$, $\left(\mathrm{W}_{1}, \mathrm{~W}_{2}, \mathrm{~W}_{3}, \mathrm{~W}_{4}, \mathrm{~W}_{5}, \mathrm{~W}_{6}\right.$ are the comprehensive evaluation value of $\left.A_{1}, A_{2}, A_{3}, A_{4}, A_{5}, A_{6}\right)$.Using 
formula: $W=\sum_{i=1}^{4} W_{i} P_{i}$ (We $(0,1]$ " very dangerous", WE $(1,2]$, "relativety danger(We ous", $\mathrm{W} \in(2,4]$ " with hidden trouble in safety" $\mathrm{W} \in(4,5]$ " safe" ), the evaluation result is "with hidden trouble in safety". In order to reach the preconcerted safety plan, measures to improve safety should be taken.

According to the results of weights value calculation, among all the first grade influencing factors, the weights value of the management factor is the largest. Namely, the management factor is the most influential .Road factor ranks the second, then, site technician factors, mechanical factors, material factors and natural environment factors.

\section{Measures to Improve Construction Traffic Safety Based on Evaluation Model}

\section{A. Improvement on management}

The current security system was revised by the construction unit after the safety evaluation," emergency plan on serious traffic accident" was made, rules and regulations improved, including: rewards and punishment system; education system on safety production; examination system on safety production $^{[4]}$.

Meanwhile, the safety responsibility was redefined and reassigned, a multi-level and cross functional steering safety assurance system was built, personnel including the director general of construction bureau, the chief engineer, leaders of all construction departments and workers from construction teams and groups. Each member's security responsibility was made clear. system diagram on safety responsibility (Fig. 1) is shown. In addition, the project department of the construction unit urged the unified management of contract workers who belongs to the subcontract unit. In this way the safety guarantee system was strengthened. One full-time safety director was set for each construction team, one part-time safety director for each construction group, all the safety directors were under the supervision and guide of the safety management department. A three-level supervisory system was built, comprising the safety management department of the construction bureau, full-time safety directors of the construction team and part-time safety directors of construction group.

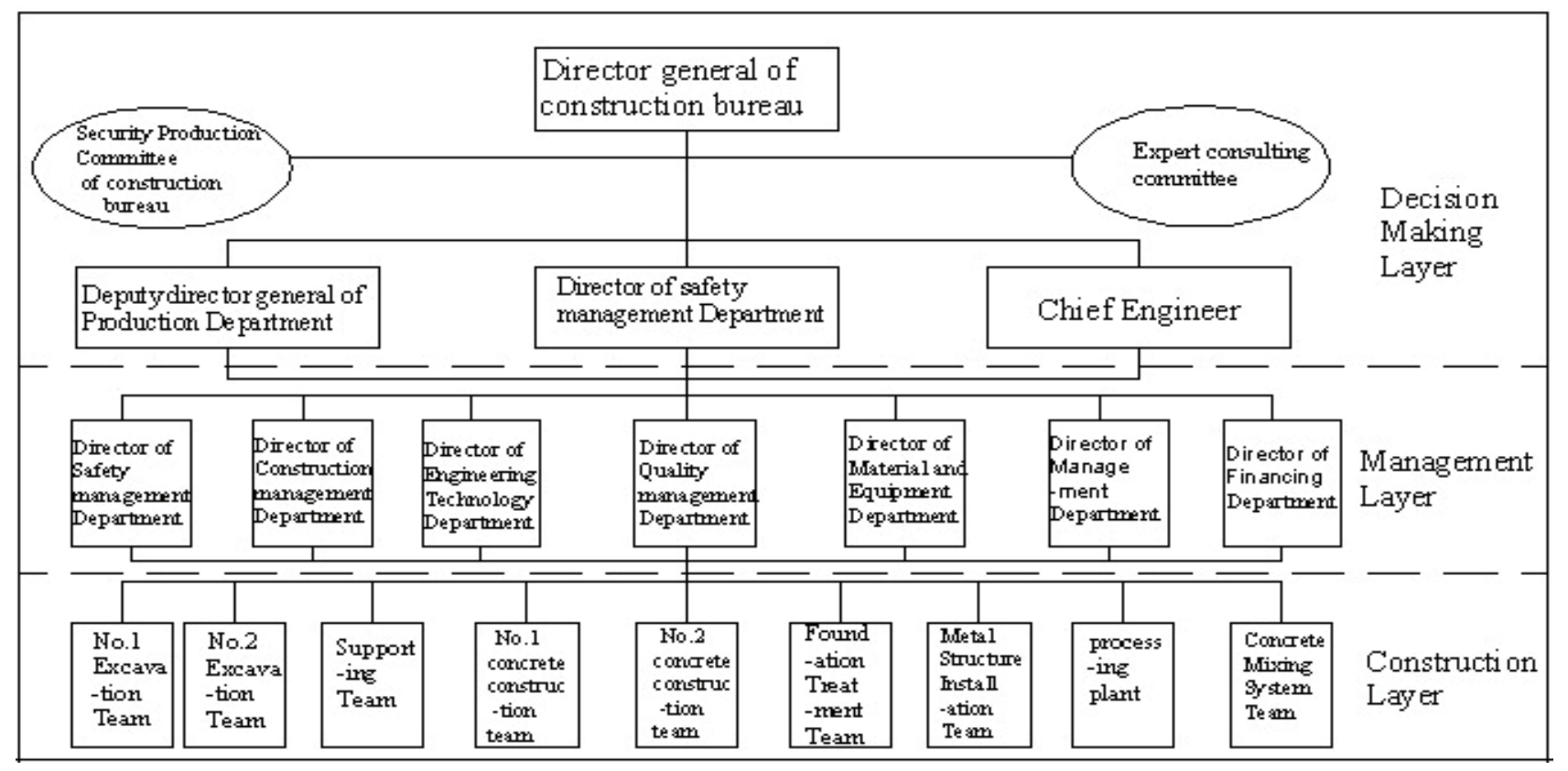

Figure1. System Diagram On Safety Responsibility 


\section{B. Safety management Optimization on construction Road}

\section{1 ) Improvement on road quality and grade.}

The grade of construction roads built at the beginning was low, (mainly grade 4), quality of the pavement was relatively poor (mainly cement-bound roads), according to the safety evaluation, the quality of current construction roads could not meet the standard of safety. So, construction roads were widened and improved, the width of the roads reached 10 meters, $95 \%$ of the pavement were hardened, whose grade reached 3.

\section{2) Measures to improve construction road Safety manage- ment}

Management confusion and unqualified construction road conditions revealed by the evaluation model, which arosed extensive attention of the construction unit. Corresponding approaches had been taken, involving such elements as:

\section{a) Improvement on HV line}

In order to prevent erroneous operations of construction vehicles, or accidents such as vehicles hung or dragged by high voltage line, the construction unit adjusted the height of the HV lines-- the terrain clearance reached $12 \mathrm{~m}$ (higher than the requirements on high voltage safety in construction site).Which, largely reduced similar accidents occurred in other construction sites.

\section{b) Crossroad Traffic control}

The construction road lead to Da Wanzi slag yard was the main lane, while, road to Guan Yinyan project department was the secondary lane. The intersection of the two roads were the main crossroad of the project, which was with large vehicle flow. Vehicles passing the main lane were mainly luck slag cars, the highest daily traffic volume reached 4558, while the slag transportation quantity 1.35 million $\mathrm{m} 3$ / day. Logistics vehicles and other local vehicles mainly used the secondary lane, whose volume was random. In order to maintain the traffic order, on the one hand, the construction unit took measures to control and regulate the traffic .on the other hand, restrict vehicles passing, set motor-driven warding off car and safety supervision staffs at the exit and entrance of the secondary lane. Measures such as limiting interval restrict vehicles flow, vehicle speed control, closing over wide crossroads, implementing the one way passing method, good results have been witnessed.

\section{c) Removable temporary security protection facilities}

Considering part of the construction road in excavation areas were narrow, slope steep turn was urgent, permanent protection facilities were still being built, the project department used the prefabricated temporary removable crashworthy concrete pier to deal with the safety problem. When using, the concrete piers were hoisted to the road side which need temporary security protection by mobile crane, when the road conditions improved, the concrete piers were transported to designated place to store, when needed, they can be used again. The measure, economical and practical, the problem of vehicle sliding off the road was well tackled.

\section{Education and Management on site construction staffs}

\section{1) Strengthen safety training and safety education ${ }^{[5]}$}

All staffs of different levels shall have the necessary professional knowledge, post knowledge and skills, master needed operation procedures, to ensure that all projects are assigned qualified personnel. Safety education programs have been created, Including: (1) consciousness safety education (2) labor regulation education (3) safety knowledge (4) education on professional safety technology (5) education on case of emergency

2) Increase staffs' initiative of safety consciousness

It's necessary for the construction enterprise to focus on people oriented management strategy, to form its unique corporate culture. So that workers will realize he is an indispensable member of the enterprise, a master of safety management. On the one hand, Enterprise should pay attention to staff's life quality, improve their accommodation conditions, to create a favorable environment for staffs. In such circumstance, workers will enjoy stable and peaceful mood, their initiative will be given full play, the ability to deal with emergencies will be improved. which, will promote the overall safety management. On the other hand, the project department attached great importance to implementation evaluation, to ensure the effect of security management. 


\section{Other improvements.}

According to the safety evaluation model, the project department has also taken corresponding measures regarding mechanical factors, material factors and natural environment factors. Approaches involves such elements as mechanical maintenance and daily inspection system, for materials, put-

\section{E. Results of second evaluation}

According to the practiced engineering of the project(after safety measures have been taken),adopting the evaluation model introduced at the beginning of the thesis to carry out a second evaluation(shown in table 1), the result is as follow: $\mathrm{W}_{1}=4.524 ; \mathrm{W}_{2}=3.957 ; \mathrm{W}_{3}=4.224 ; \mathrm{W}_{4}=4.227 ; \mathrm{W}_{5}=4.730$; ting forward planned procurement, quantitative distribution, reasonable reserve to ensure safety production, cost saving and unified management. Emergency measures on construction in winter and rainy seasons, as well as plans on construction during high temperature weather have been made.

$\mathrm{W}_{6}=3.610$, Using formula $W=\sum_{i=1}^{4} W_{i} P_{i}, \mathrm{~W}=4.445$. The defined safety degree is "safe" ${ }^{[6]}$. Evaluation results have met the expected effect. During the construction of the diversion channel project of Guan Yinyan hydropower station, no traffic accident occurred.

TABLE 1. Second evaluation on construction traffic safety

\begin{tabular}{|c|c|c|c|c|}
\hline Object Hierarch & Rule Hierarchy & Index Hierarchy & Weight $(\mathrm{P})$ & Expert Scoring \\
\hline \multirow{24}{*}{$\begin{array}{l}\text { Comprehensive } \\
\text { Evaluation Index } \\
\text { on Construction } \\
\text { traffic safety risk }\end{array}$} & \multirow{4}{*}{$\begin{array}{l}\text { Management Factor In- } \\
\operatorname{dex}\left(A_{1)}\right.\end{array}$} & Management System $\left(\mathrm{A}_{11}\right)$ & 0.1726 & 4.8 \\
\hline & & Safety Responsibility $\mathrm{A}_{12}$ & 0.2856 & 4.5 \\
\hline & & Safety Culture $\left(\mathrm{A}_{13}\right)$ & 0.0555 & 4.0 \\
\hline & & Safety Supervision $\left(\mathrm{A}_{14}\right)$ & 0.4863 & 4.5 \\
\hline & \multirow{4}{*}{$\begin{array}{l}\text { Site Technician Factor } \\
\text { Index }\left(\mathrm{A}_{2}\right)\end{array}$} & Education Background $\left(\mathrm{A}_{21}\right)$ & 0.1191 & 3.6 \\
\hline & & Training Background $\left(\mathrm{A}_{22}\right)$ & 0.5702 & 4.2 \\
\hline & & Age $\left(\mathrm{A}_{23}\right)$ & 0.0588 & 3.0 \\
\hline & & Technical level & 0.2519 & 3.8 \\
\hline & \multirow{4}{*}{$\begin{array}{l}\text { Machinery Factor In- } \\
\operatorname{dex}\left(\mathrm{A}_{3}\right)\end{array}$} & Machinery Regulation Condition $\left(\mathrm{A}_{31}\right)$ & 0.2771 & 4.0 \\
\hline & & Mechanical Quality $\mathrm{A}_{32}$ & 0.4659 & 4.3 \\
\hline & & Purchase $\quad\left(\mathrm{A}_{33}\right)$ & 0.0800 & 3.5 \\
\hline & & Machinery Maintenance and repair $\left(\mathrm{A}_{34}\right)$ & 0.1770 & 4.7 \\
\hline & \multirow{4}{*}{$\begin{array}{l}\text { Material } \\
\operatorname{dex}\left(\mathrm{A}_{4}\right)\end{array}$} & Purchase of protective articles $\left(\mathrm{A}_{41}\right)$ & 0.2559 & 4.5 \\
\hline & & Purchase of Protective Articles. $\left(\mathrm{A}_{42}\right)$ & 0.1156 & 4.2 \\
\hline & & Material Quality $\left(\mathrm{A}_{43}\right)$ & 0.4763 & 4.0 \\
\hline & & Material Management $\left(\mathrm{A}_{44}\right)$ & 0.1522 & 4.5 \\
\hline & \multirow{4}{*}{ Road Factor Index $\left(\mathrm{A}_{5}\right)$} & Road Technical Standard $\left(\mathrm{A}_{51}\right)$ & 0.1398 & 4.8 \\
\hline & & Road Quality $\left(\mathrm{A}_{52}\right)$ & 0.4766 & 4.8 \\
\hline & & Road Junction $\left(\mathrm{A}_{53}\right)$ & 0.0870 & 4.0 \\
\hline & & Road Maintenance $\left(\mathrm{A}_{54}\right)$ & 0.2966 & 4.8 \\
\hline & \multirow{4}{*}{$\begin{array}{l}\text { Environment Factor In- } \\
\operatorname{dex}\left(\mathrm{A}_{6}\right)\end{array}$} & Geological Conditions $\left(\mathrm{A}_{61}\right)$ & 0.4723 & 3.6 \\
\hline & & Seasonal Factor $\quad\left(\mathrm{A}_{62}\right)$ & 0.0725 & 3.2 \\
\hline & & Influence of rain and snow $\left(\mathrm{A}_{63}\right)$ & 0.2854 & 3.5 \\
\hline & & Night Construction $\left(\mathrm{A}_{64}\right)$ & 0.1697 & 4.0 \\
\hline
\end{tabular}

\section{Conclusion}

In this paper, according to the evaluation model using Fuzzy Analytical Hierarchy Process (FAHP) on construction traffic safety, influential safety factors of the project have been found, including: management factors, site technician factors, mechanical factors, material factors, construction road factors and natural environment factors. Corresponding 
measures(i.e, building a multi-level and cross functional steering safety assurance system;improving road quality and HV line; crossroad traffic control; adopting removable temporary security protection facilities; motivation and training on staffs.) to improve project construction traffic safety have

\section{REFERENCE}

[1] "Construction Organization Design of Guan Yinyan hydropower project”. No.7 bureau of Sinohydro,2009. Unpublished.

[2] YANG Xiaoyan, XIE Xinsheng, NIU Yaping, "Study on evaluation model of construction traffic safety of hydropower project”. J. Southwest jiaotong university journal supplement.in press.

[3] ZHOU Ke "Evaluation System of Traffic Safety Based On Road Factors" D,ChongQing ,ChongQing jiaotong been elaborated. Then, a second evaluation based on the model been carried out, the calculated result is "safe". In engineering practice, these measures have been proved applicable and efficient. university,2009

[4] YE Jianwen"research on safety problems and approach in hydroper poject construcion "J.Modern Business,2010,24.

[5] LI Qiang" safety education and training on construction enterprise".J. Economic and Social Development,2011,2.

[6] YANG yingjiu ."Optimization of Fuzzy Mathematics for Selection of Arcthitectural Construction Alternatives" J.Journal of Wuhan University of Hydraulic and Electric Engineering,1988,01 